\title{
Historical Contexts and the Construction of Twenty-first Century Asian Art Worlds
}

\author{
SAMUEL K. PARKER
}

Our hearts should go out in sympathy for anyone aspiring to make serious art today. The art game is about the making and marketing of brands. The objects themselves are incidental, and thus, formalist talk about aesthetic values primarily serves to promote unconsciousness, deflecting attention away from the dominant, monetary values organizing the game. Accordingly, art criticism is best focused at the level of the public system. In his recent book, On Bullshit, Princeton philosopher Harry Frankfurt observes that we are presently immersed in a public world rich in bullshit (Frankfurt 2005). One of the main jobs of scholarship should be to pick up a shovel and help clear away the mess, and nowhere is this more necessary than in the world of fine art. This isn't because of the use of big words or complex sentences, commonly mocked in anti-intellectual segments of popular culture. Jargon and complexity are fine so long as they are not being used to conceal a lack of substance. And even if clearing away bullshit is not going to unearth absolute-eternal and infinite-Truth, we can still hope that there is value in disposing of historically constructed untruth. So where's the shovel? In their introduction to a recent collection of essays titled Asian Material Culture, the editors boldly assert that in these days 'the methodology of material culture can be condensed into a single word: context' (Hulsbosch, Bedford and Chaiklin 2009: 13). One might be tempted to reply, so what? Why is this claim significant? In what sense is this perspective anything new?

If you're a hard-core modernist, you've already been-there-donethat - context is yesterday's news. Way back in the late 1970s a group of studio art students at the University of Hawaii (myself included), in loose collaboration with visiting New York conceptual artist Joseph Kosuth and our intellectual mentor Prithwish Neogy (a tireless shoveller himself), staged an art exhibition somewhat naively titled, Let's put it in the Context. In those days, before we had a name to refer to the seismic shift we now call 'postmodern', even undergraduates way out in the middle of the Pacific Ocean were aware that the heroic modernist search for the Essence of Art had passed its expiration date. The old pro- 
gressive, avant-garde modernism in which we had all been socialized, implicitly presumed art to be a natural, universal category, defined by a mysterious internal essence common to every genuine work of fine art, whether recognized as such or not. Modernists sharply differed on what that essence was, but until the 1970s few doubted its existence. Accordingly, the game of modernism we art students had been trained to play entailed a serious, principled practice of stripping away everything incidental to this essence in hopes that eventually the universal nature of 'art' would be systematically revealed in all its pristine purity - and presumably, art history would at long last be terminated by a final determination of absolute right and wrong. ${ }^{1}$ But by the mid-1970s many of us were becoming aware that the 'essence' of art was, in fact, nothing internal to the independent object itself. Essence is a mirage, arising out of the ever-unfolding relation of the object to what we naively called 'the context' in our exhibition.

Our use of the definite article 'the' referred to 'the' art context. We didn't yet fully realize in those days that by turning our backs on modernism's abstract, universal essence we were automatically turning toward a concrete, particularistic embrace of aesthetic pluralism. 'The' art context had, in fact, always been a complex system, composed of many art worlds - including regional ones in Asia and elsewhere - that had been concealed by the fake universals underwriting modernist myths.

These concealing functions had been partly described by the British art critic John Berger in his popular book, Ways of Seeing (1972), which was generating a stir in college art departments at the time of our exhibition. Berger explained that the ornate, formalist rhetoric informing most modernist discourses about art were, in fact, 'mystifications', or in other words, bullshit, intellectual talk focused on the fetishizing of pure form, which, behind the scenes, primarily functions to deflect attention away from the obvious. The obvious being the relentlessly capitalist model of economic value that, in fact, had come to dominate the contemporary systems through which art objects are routinely used and interpreted.

\section{The Globalizing Aesthetic Contexts of an Economic Cosmology}

More than 35 years have passed since those early stirrings of what we now call postmodernism, and yet they have still neither been widely digested at the intellectual level nor seriously integrated into the practices of globalizing pop culture. Indeed, the idea that postmodernism itself is 
old news reveals that the linear historical mythologies of modernism are very much with us. Thomas McEvilley uses the phrase 'residual modernism' to describe the ubiquitous survival of modernist presuppositions at the level of everyday practice and discourse (1992: 138). Under the guise of post-this and neo-that, a modernist form of novelty-oriented valorization - that is to say, a belief in utterly discontinuous acts of 'creativity' - continues to flourish, except that it now lacks modernism's serious sense of principled value and purpose. And as usual, whenever the values intrinsic to any domain of practice become seriously corrupted, the market is always ready to fill the vacuum with an empty, quantitative form of universalizing value, symbolized by money. Modernist 'creativity' thus degenerates to its contemporary default position, as the legitimizing principle of private intellectual property rights.

Accounting mechanisms of popularity and sales gradually step in to assign value while the substantive, qualitative values of truth, beauty and wisdom - formerly pursued through the arts - are eroded in the public sphere. We don't broadly agree on what makes a true or beautiful representation (or even if beauty is relevant to the arts at all), and so we lazily let the market decide: what counts as 'aesthetic' value is subsequently established, more and more, by the discipline of the market, at auction. ${ }^{2}$

Let it be clear that I do not mean to suggest that the qualitative values traditionally pursued through the arts have been simply abandoned. Rather, they are so embattled in the context of our adversarial public life that they have been largely relegated - like spirituality - to an isolated, independent, or individualistic sphere, where values are treated like sovereign private property. They are tacitly reified as if they were private 'things' that a possessive individual 'has'. Of course, beauty, truth, insight, etc. continue to be valued by many who care deeply about the arts and their potential, but they are nowadays typically framed as subjective, 'eye of the beholder' phenomena-a prime example of Frankfurt's 'bullshit' - and therefore as irrelevant to the 'real world' (by which folks commonly mean money and power, more or less two sides of the same coin in a practical world organized by market mythologies).

While residual modernism thrives in the darkness of practical, unconscious routines, the alibis of 'difference' (quickly fetishized by modernist values as unique identity), irony, play or whimsy commonly operate in the open light of day, shaping the popular aesthetic surfaces of 'postmodern' varieties of modernist art practices (as much as it does the commercially ornamented surfaces of tattooed, pierced and surgically 
altered 'postmodern' bodies). But a pinch of fetishized difference and idiosyncratic whimsy goes a long way in the art world. A lot of it starts to become tedious. And so, as the routine quirkiness of contemporary art in the West increasingly fails to excite, doors to fame and fortune are opened to certain Asian artists who are able to breathe some fresh life into the game by marketing regional 'brands' of difference, idiosyncratic quirkiness, grounded in the visual cultures of other times and places. Chinese artists in particular have managed to position themselves as the darlings of well-heeled art collectors in the early twenty-first century, with their Indian counterparts following closely behind. This pattern tellingly parallels the volatile love affair going on between glamorous Chinese markets and wealthy capitalist suitors in the West, a romantic comedy in which India plays bridesmaid. But it isn't really so much that these two valorizing contexts are simply parallel, as that they are both part and parcel of the same thing: that is, the systemically rewarded mirroring of a peculiar globalizing political-economic cosmology actively working to conceal the fact that it is a human system of semiotic representation. That is to say, the globalization of elite art markets serves to allow a historically peculiar economic cosmology to persuasively masquerade as the universal real world, natural and inevitable. In this way the contemporary Chinese art phenomenon has a direct cosmological utility for the concentration and legitimization of amassed capital, even if relatively few captains of industry actually ever become serious players in contemporary art markets. Art obviously provides for them an additional space of relief for problems posed by the immense concentration of wealth. What to do with it all? Obviously one can always gamble with the herd on the price fluctuations of stocks, currencies or commodities, but fine art offers a high-end mode of identity-construction, marked by insider intrigue, glamour, competitiveness and social cachet lacked by other mundane kinds of speculation (see Note 2). But it isn't for everyone, and that seems to be a big part of the appeal. As Pierre Bourdieu has shown, French communities of taste are formed around art forms that supply semiotic markers of distinction that seemingly naturalize the innate superiority of haves over have-nots, as if hierarchy is the simple outcome of differences in character (Bourdieu 1984). And when it comes to the fine arts, France has had more impact on the shaping of the modernist system than any other nation-state. 


\section{Is Asian Fine Art Useless?}

Morgan Pitelka, one of the editors of What's the Use of Art? Asian Visual and Material Culture in Context, reminds the reader that we should not delude ourselves into thinking that our

understanding is derived entirely from the objects themselves. It is these strata of value - a kind of stratigraphy of meaning deposited in sedimentary fashion through centuries of use, circulation, and objectification that determine not only the identification but the experience of encountering [Asian art objects] (Mrazek \& Pitelka 2008: 1).

The ongoing need for arguments like this clearly shows that the so-called postmodern turn away from essences and toward systemic contexts of use has turned out to be, not an event, but an emerging, decades-long process that, in the second decade of the new century is not, even yet, widely swallowed, let alone digested in the living practices of the art world. Instead, routine practices in various art worlds remain infused by a residual modernism, including the fetishized mode of antiessentialist difference that often represents itself as postmodern, but is in fact simply the perpetuation of an inverted, mirror image version of modernist cosmology. The 'art worlds' theme of this present collection, similarly encodes a critical understanding that works of Asian art are not historically discontinuous, or, like modern persons, essentially 'free'. They do not have independent or inherent value in themselves, rather they exist and acquire value only in relation to the historical human contexts of their production, use and continuous re-use. ${ }^{3}$ In short, as long as a residual modernist, market cosmology remains uncritically naturalized in our language, our institutions and our popular bullshit discourses about the 'real world', it appears that it will be necessary to continue to argue, again and again, that the significance or value of a work of art does not really arise out of a universalizing conception of abstract, internal essences, independent of temporal circumstances. It arises out of the object's sociocentric relation to concrete contexts.

\section{Does 'Asian Art' Really Come from Asia?}

From the eighteenth through the early twentieth century it was simply presumed that Chinoiserie, Orientalism, Japonisme and Primitivism - in that historical order (more or less) - were inherently strange and 'exotic'. However, today it is appropriate for us to acknowledge that it was the Western 'art' concept itself that was becoming exotic 
during that period. The traditional material culture of the non-Western world is not, and has never been, exotic; however, what counts as fine art in the contemporary art market today certainly could be justifiably described as such.

As the Enlightenment roots of progressive modernism were watered in the nineteenth century, authentic objects of 'fine art' - wherever in the world they may have been 'discovered' - slowly came to be universally defined by a mysterious, quasi-religious essence, somehow encoded in form (McEvilley 1992: 17-25). According to The Concise Oxford Dictionary of Art and Artists, the idea of the '..."fine arts" arose in the 18th century to separate the class of "higher" non-utilitarian arts from applied or decorative arts...' which are defined in turn as '... art that is used to decorate or embellish an object that has a practical purpose, as opposed to fine art, which exists as an end in itself. ${ }^{14}$ But by what signs could one tell if an Asian object was 'art' or something else? Uselessness could be one criterion, but that alone is not sufficient. By the early twentieth century, the art critics Roger Fry and Clive Bell codified influential formalist principles of value, in their concepts of 'significant form' and their embrace of the late nineteenth century French slogan, l'art pour l'art, 'art for art's sake'. Even though this kind of essentialist formalism was opposed by alternative early twentieth-century developments such as advocates for the Arts and Crafts movement and the Bauhaus, who held that forms should be integrated with practical functions, and by certain political and commercial interests, who held that art should serve the purposes of propaganda/advertising, for the most part, elite modernist practice pursued the formalist vision of fine art.

The problem is that even if 'fine art' is ineffably encoded in form, it is not simply reducible to it. Essentialist formalism is mysterious. The absence of any clearly perceptible common attribute distinguishing art from non-art provided rich soil for the growth of a lush jungle of theoretical rhetoric, irreverently deconstructed by Tom Wolfe in his 1975 classic, The Painted Word. And because enormous sums of money are at stake in modernist fetishizing, collecting and exhibiting practices, the translation of essential value into cash value requires the services of a special type of person possessed with mysterious powers of taste and perception: the connoisseur. The fact that the connoisseur traditionally represents members of a class of great wealth and prestige, usually inherited 'old money', whose essential value - like that of the fine arts themselves - mythically transcends utility, is similarly overlooked or treated as irrelevant to the act of connoisseurship (Price 2001: 7-22). 
What is considered central to connoisseurship is public confidence in the Great Man's capacity to correctly perceive the universal essence of quality marking all great works of art, regardless of the culture, or historical period, or original reasons for which they were made (McEvilley 1992: 17-25).

As Western art practice in the late nineteenth and early twentieth centuries became increasingly shaped by an essentialist mythology of art and a linear model of historical progress, its novel products naturally appeared at first to be unfamiliar, strange, even offensive to connoisseurs and assorted experts. But ironically, as soon as members of the art establishment attack an upstart rebel, he is automatically drawn into the art world. He (rarely she) is instantly part of the allimportant conversation. Accordingly, the initial strangeness of Asian visual languages began to be an automatic plus when seen through eyes increasingly conditioned by the routine controversies and celebratory triumphs of the modern art game. Many Asian and 'Primitive' collectables superficially appeared to modernists as if they, too, exhibited signs of individualistic self-expression and artistic freedom from the conventions of nineteenth-century academic realism. And so it is not surprising that, like fauvism, cubism, rayonism, suprematism, surrealism, etc., certain analogous schools of Asian art objects were 'discovered' to be fine art, and subsequently absorbed, normalized, processed and digested by a modernist art system, organized around a system of concrete practices, including collecting, buying, selling, documenting, conserving, cataloguing and exhibiting. While to some this may have appeared to be a generous act on the part of Western art institutions, bestowing universalized humanity and artistic celebrity on mostly anonymous, non-Western others (Price 2001), it did not come without a price, paid in the currency of bullshit: taxonomic confusions, essentialist mystifications, formalist smokescreens and subsequent misrepresentations (Mrazek and Pitelka 2008).

\section{Articles in the Current Volume}

Thus, the present volume contributes in a modest way to a long-term project of re-contextualizing the 'Art of Asia' through restoring recognition of the relational (or contextual) functions long obscured and/ or obliterated by modernist practices. Contemporary research aimed toward re-establishing the functions - or uses - of art, including essays offered in the present collection, tend to show two primary faces. First is that 
of the contemporary political-economic uses of art. ${ }^{5}$ The second is a bit more subtle, embodied in efforts to engage and understand Asian artefacts - as objectifications of another time, place and value frame - for the purpose of cultivating sympathetic identification and reciprocal nourishing of our collective intellectual and spiritual growth.

The latter is not just a matter of Westerners understanding Asian art per se, but represents the historical emergence of cross-cultural collaborations, in which complex global world-views are slowly being negotiated and co-created. Speaking to this usage, Roger Ames observes that the contemporary effort to interpret and understand the arts of distant times and places in Asia,

has the potential to liberate and animate our own responsibility as cocreators... in allowing objectivity and orthodoxy to recede, we are renewed as unique, historical and provisional beings who struggle with imagination to quite literally make sense out of what is at first nonsense.... Indeed, it is this 'authentic temporality,' our own historicity, that is the mystery and inspiration of art... What is at stake in the liberation of our historicity is the renewed possibility of the aesthetic and religious quality of experience itself (2011: 14).

At this point a few remarks contextualizing each of the essays contained here may help the reader avoid getting lost in the jungle of specific cases and keep an eye open to a larger frame to which they speak.

'The Wasteland of Creative Production: A Case Study of Contemporary Chinese Art' critically exposes some of the romantic mythologies that have underwritten the recent popularity of contemporary Chinese art among elite collectors and the experts who write about it. Despite the popular branding of contemporary Chinese artists as if they were countercultural 'Great Men' struggling for the freedom of 'self-expression' against an oppressive status quo (here the state rather than the art establishment), empirical evidence shows that, on the contrary, contemporary Chinese art is more often the communally organized product of an official, state-sponsored culture industry strategically positioned to exploit the money-driven world of contemporary art.

The ancient Japanese aesthetic orientation toward innocence and cuteness called kawaii can be traced back to the early Haniwa tomb sculpture of the fifth century. While it has long been one among many visible aesthetic values in Japan, it has lately moved from its formerly minor role to one of much greater prominence, as the youth-oriented tastes of a popular culture, organized around the production and consumption of mass-produced goods, takes centre stage, while the aes- 
thetics of aristocratic and samurai classes fade into the background. The article included here, 'Cute and Cool in Contemporary Japanese Visual Arts', explores the critical force of kawaii in Japanese popular culture, the corresponding neo-pop tastes prominent in the Japanese world of contemporary fine arts, and the opportunistic appropriation of kawaii by Japanese politicians in the branding of Japanese national identity in the international arena, where a characteristically Japanese variety of 'soft power' is being asserted.

In the late 1970s, supported by shamelessly commercialized promotion by Andy Warhol, specialized adaptations of urban graffiti began to be deliberately crafted for sale in elite New York and Italian art galleries. In one sense this was just another recycled variant on the old 'outsiderart' category of collectables that had waxed and waned throughout the previous century. But in a narrower sense, as the mythical cuttingedge-of-the-future faded during the 1970s, an edgy excitement generated out of the linkage of graffiti to criminal vandalism, allowed the art market to briefly squeeze a little more life out of the old modernist narrative. The third article presented here, 'Graffiti in China - Chinese Graffiti?' examines graffiti as a globalizing pop-culture phenomenon, legitimized in the 1980s by High Art, which becomes profoundly qualified when practiced in Chinese urban contexts, where the making of formal and informal public inscriptions have been routine practices since antiquity. In China, public acts of graffiti are not automatically classified as criminal defacements of 'private property' (a notion that itself has a problematic history in China). Thus, not only does graffiti blur the distinction of popular visual culture and contemporary fine art in locally distinctive ways, the Chinese authorities tend to be more tolerant of the practice than their Western counterparts, so long as it avoids undesirable political content.

Like many other modern nation-states arbitrarily formed around the high-water mark of colonial power, Indonesia struggles with the semiotic problem of national identity. Because of the public visibility of the built environment, and because across the globe, the modern field of professionalized architecture is shaped by either resistance or conformity to the Bauhaus International Style, architectural aesthetics are a particularly problematic domain for many non-Western projects of identity construction. 'Negotiating Architecture Worlds in Indonesia: The Work of Eko Prawoto' sheds light on these broader issues with reference to a specific nation-state and the practice of a specific architect, Eko Prawoto, whose work is informed by modernist professionalism but 
not simply determined by it. Instead of imitating the formalism of the Bauhaus, or its exact inverse-expressed in the modernist fetishizing of supposedly static, timeless or 'traditional' architectural forms - Eko Prawato deploys an alternative form of 'critical regionalism' centred more on local processes than on local forms. Asian architects like Eko seek to grow appropriate architectural forms out of the historical and environmental depths of local cultural and community traditions rather than mechanically copy the kind of picturesque, timeless formalism through which modernism itself has falsely fetishized 'traditional' architecture. In this way, Eko's work eloquently exemplifies the relational values of co-creativity discussed above.

The modernist work of inventing 'tradition' as an aggregate of timeless, ideally static values and forms operates with a vengeance in the sometimes uneasy alliance of the Archaeological Survey of India (ASI) and the mix of public and private organizations labouring to excite, shape and exploit the appetites of foreign and domestic tourists for monetary gain. 'Lived Cosmologies and Objectified Commodities: Reinventing the Traditional Art of India in a World of Cultural Tourism' examines the contemporary subordination and re-framing of ancient South Asian monuments in service of the relentless 'real world' economic values that institutionally mediate the visitor's experience. Meanwhile, the spiritual values through which these monuments have been historically made and used are re-positioned as if they were the static corpses of a dead past. A visitor inclined to engage these monuments as embodiments of living spiritual values - rather than resources of and for the false naturalization of a globalizing, economic worldview and its correlated monetary semiotic system - is forced to do so through subtly subversive acts of resistance to the static, authoritative and 'authentic' framing of monuments offered for sale by the ASI and the tourist industry.

In sum, each of the essays included in this open-ended and wideranging collection offers some empirical evidence and a number of hints on how the emergent dynamics of globalizing political-economic contexts operate in different parts of Asia to actively construct significance and value, of and for 'art' objects in the twenty-first century. Here we are able to do little more than point toward phenomena that emerge out of systems of relation that are not only immense, but ultimately even transcend the limitations of verbal representation. Thus, to say that we are not telling the whole story here would be a spectacular understatement. 


\section{NOTES}

1 Marcel Duchamp represented this process through his metaphor of 'the bride' (art) being 'stripped bare by her bachelors' (modern artists). Duchamp metaphorically represented this stripping process as a game, specifically for him, something like chess, which ultimately ends in checkmate. Avant-garde modernism finally reached the point of checkmate in the late 1960s and early 1970s. When modernist 'art' was finally stripped down to its essence and the artistic freedom of the avant-garde was absolutely unhindered, there was nothing left to 'art' but the radical gesture. Duchamp's final work, Etant donnes, installed in the Philadelphia Museum of Art in 1969, is a sculptural panorama requiring the viewer to look through a peephole to see the nude, spread-eagled bride, harshly illuminated, ravaged, dismembered and tossed out in an open field. For Duchamp, as for many who deeply care about art, modernism and its aftermath has not exposed the universal, shining Essence of Art, but a story of insults inflicted on the bride's mutilated remains. Once the underlying structure of the modernist game became widely recognized, it became impossible to be radical anymore. By the 1970s, if I tried to be radical, I'd be simply behaving like any normal modernist.

2 As I write these words, an article in my local newspaper cites the 'healthy returns' of investors who follow the Mei Moses All Art Stock Index. The reader is warned however, that anything you buy for less than $\$ 5,000$ is not really investment grade art, noting that 'the average purchase price across the index is $\$ 120,410$ '. So unless you are rich and able to pay for consultants with high levels of market expertise, the world of art investment is not for you (R. Channick, 'Jaded investors turn to alternatives'. The News Tribune. Tacoma, Washington, 28 July 2011: A15). More narrowly to the point of this volume, a recent issue of The Economist (23 July 2011: 79-80) describes the 'wild, wild world of the Chinese contemporary art market' as an exciting 'experimental' world of personalities, profits and perils for courageous investors. The essay frames the challenges of the contemporary Chinese art 'brand' through the lenses of government restrictions on freedom (i.e., the old engine of avant-garde modernism) and the lack of solid Chinese institutions (e.g., museums of contemporary art) that would provide confidence to would-be buyers of contemporary Chinese art that what they are buying has substantive value. For naive outsiders like me, if contemporary Chinese art is really the branding and confidence-game described by The Economist, then it is best played by super-rich adrenaline junkies with money to burn and a smart exit strategy.

3 James Clifford provides a useful semiotic model of how the modern art-culture system operates in his book, The Predicament of Culture (1988: 215-254).

4 'Decorative art'. The Concise Oxford Dictionary of Art Terms. Ed. Michael Clarke. Oxford University Press, 2001. www.oxfordartonline.com, accessed 10 June 2011.

5 The danger of this approach is that it can easily devolve into simplistic political or economic reductionism.

\section{REFERENCES}

Ames, Roger. 2011. 'Re-Iconizing Artifacts: Using the Curriculum to Recontextualize Asian Art'. In Reading Asian Art and Artifacts: Windows to Asia on American College Campuses, edited by Paul Netupski and Joan O'Mara. Lanham, MD: Lehigh University Press.

Berger, John. 1972. Ways of Seeing. London: Penguin. 
Bourdieu, Pierre. 1984. Distinction. London: Routledge.

Clifford, James. 1988. The Predicament of Culture. Cambridge: Harvard University Press.

Frankfurt, Harry. 2005. On Bullshit. Princeton, NJ: Princeton University Press.

Hulsbosch, M., E. Bedford, and M. Chaiklin. 2009. Asian Material Culture. Amsterdam: Amsterdam University Press.

McEvilley, Thomas. 1992. Art and Otherness: Crisis in Cultural Identity. New York: McPherson.

Mrazek, J. and M. Pitelka. 2008. What's the Use of Art? Asian Visual and Material Culture in Context. Honolulu: University of Hawaii Press.

Price, Sally. 2001. Primitive Art in Civilized Places. Chicago: University of Chicago Press.

Wolfe, Tom. 1975. The Painted Word. New York: Farrar, Straus \& Giroux. 